\title{
The analysis of strategies for the mining regions' development in Russia as a condition of effective management of economy
}

\author{
Natalya Zaruba ${ }^{1,{ }^{*}}$, Natalya Egorova $^{1}$ and Peter Kosinskij ${ }^{1}$ \\ ${ }^{1}$ T.F. Gorbachev Kuzbass State Technical University, Department of State and Municipal \\ Management, 650000 Kemerovo, 28 Vesennya st., Russian Federation
}

\begin{abstract}
The conceptual issues of a new approach in the implementation of strategic management development of the coal-mining region as conditions of effective government regulation of economy at the macro level are considered in the article. The purpose of the study is to justify the use of marketing techniques in the strategic management of the region, clustering on the basis of the territorial concentration and combination of all available resources, the integration of regional economic networks. A comparative analysis of the main strategic directions of development of the coal-mining regions from the point of view of the leading economic development strategies is carried out. The main result is that the estimation of value of synergy effects occurring when the resources of combining sectors and industries in the region are united has been made. The results of the study can be recommended for usage in the development of strategies for sustainable development of «mono-territory».
\end{abstract}

\section{Introduction}

The relevance of analyzing the strategies of mining regions as a condition of effective government regulation of Russian economy is justified, first of all, by the problems of the economy itself.

The current state of Russian economy requires new solutions in the theory and practice of management, including the development of innovative strategies for regional development, as the promising areas of competitive production of definite goods (and services), jobs and high living standard for the population.

Modern economic problems cause the need for taking measures adequate for market conditions in the regional strategic management. They should become conditions for effective state regulation of the economy as a whole. Such measures we believe will help to ensure effective functioning and future development of the most complex structure-forming areas.

The centers where such transformations take place are the regions where the real management tools of economic systems are concentrated. A comprehensive innovative approach to the management of such territory implies not only the system of goals and

\footnotetext{
*Corresponding author: zaruba@kuzstu.ru
} 
objectives of the authorities in management of all sectors of the economy, but also mechanisms for their implementation, which requires, in turn, the need for analysis of the strategies of such territories.

Rational regional policy management directed to the development and implementation of such mechanisms must be based on multidimensionality and importance of its role in the development of regional economy. At the same time the priority of regional development strategy should be given to that in which the region acts as a single economic system, integrated territorial product.

We believe that such strategy should be based on an innovative approach to management which, in our opinion, can be considered marketing approach to clustering technology, as it allows, first of all, taking into account the specifics of territories, their resource, social and economic and other features, and also it is based on the possibility of getting a synergistic effect in management.

The scientific novelty of the work lies in the theoretical and practical substantiation of diversification of regional strategic management by clustering and the synergies from the combination of all its resources.

\section{Results and Discussion}

The need for the formation of a new management strategy of regional development comes from the ever-changing economic situation in and around the region.

It should be emphasized that the highlighted problems today are quite popular in the scientific literature. Many experts are studying the issues of strategic management of regions, but, despite this, a number of problems remain under discussion [1-5]. Particularly relevant and unsolved, in our opinion, is the problem of mono-territory management.

In addition, the existing approaches to the definition of "strategic management" do not reflect, in our opinion, the individuality of territories. For example, O.S. Wihansky defines the regional strategic management as a certain philosophy or ideology of business and management, not pointing to a specific decision making and regional specific. [6]

It is important to note that today there is a variety of regional development strategies, which are aimed at ensuring social and economic indicators growth without defining it as a complex product able to represent its individual specifics on the market. In connection with this we emphasize that the solution of the problem of the territory's sustainable growth is possible only through an integrated approach to the strategic management of the regional economies, thus it becomes objectively necessary to develop a concept territory's promotion, which would structurally reflect and address all industries and sectors of economy.

In addition, the development of the clustering concept on the basis of the territorial concentration and combining all available resources we should take into account the differentiation of territories. We should distinguish them by not only the availability of resources, mineral resources, specialization, but estimate the reserves for the innovative development of regional economy. Particularly vulnerable in this sense are the regions in which heavy industries have been and remain the basic ones, without reducing the role of these industries and their importance in the development of the regions, we consider it necessary to "modernize" management in terms of its effectiveness growth.

To these regions, in our view, should be referred the mining regions of Russia. It should be noted that in the Russian Federation various types of coal (brown, anthracite and hard coal) are mined. As for coal reserves Russia is one of the leading economies in the world. Two thirds of the total volume of coal is hard coal. Russia is on the fifth place in coal production and it is important to note that a substantial volume of coal (the half of Russian coal production) is concentrated in Kuznetsk Basin. Almost 95\% of reserves are 
concentrated in the east of the country, more than $60 \%$ in the Siberian Federal District (SFD).

In $201584.5 \%$ of total coal amount was produced in Siberian Federal District, $9.4 \%$ - in Far Eastern Federal District; 4\% - in North-West Federal District; 1.3\% - in Southern Federal District; $0.5 \%$ - in Urals Federal District; 0.2\% - in Volga Federal District; $0.1 \%$ in Central Federal District. As we can see, the "lion" share of mined coal is accounted for SFD.

All this testifies the positive dynamics of the development of coal industry, which is the factor determining the growth of the Kemerovo region's economy as a coal-mining region. However, despite the positive trend of coal industry development in Russia as a whole the demand for coal will rise to 2020 as analytics predict. Then this kind of fuel consumption will gradually decline, which is associated with increasing consumption of natural gas in future.

These possible changes in market conditions are not in favor for coal mining industry and today coal-mining region authorities, in particular, the Kemerovo region, should pay attention to possible risks and threats of "mono-dependent" economy.

Defining innovative steps in the regional management, we believe it is necessary to conduct a comparative analysis of strategies for social and economic development of two the most leading mining and coal reserves territories: Kemerovo and Sakhalin regions.

Analyzing the strategies of Russian coal mining regions, we consider being necessary to examine the management advantages and disadvantages in order to identify the so-called "bottlenecks" and provide their subsequent elimination, reduction to the optimum denominator.

It should be noted that based on the objectives and goals of the studied development strategy, Kemerovo region should be referred to the export-oriented regions of Russia. The basic sector in the structure of regional economy is the extraction and primary processing of natural resource - coal.

At the same time, it is important to emphasize that the strategic development of Kemerovo region, as well as other coal-producing regions, in the first place will depend on the dynamics of the social and economic situation in the country, on the global market and regional product (coal) competitiveness.

This means that in the near future, the inertial development of the region only by strengthening the competitiveness of the coal industry is most likely to be. Realizing the importance of keeping the coal industry as the base for the regional economy, we believe that in the long run it is especially important to take into account the risks that may arise in industrial mono-specialization, such as the dependence of the entire regional economy on the situation on a separate market segment (coal), especially globally.

Moreover, such limitation of the regional economy within only heavy industries will lead to disproportionate structural shift in general and increasing "mono-dependence" of economy.

We believe that especially "vulnerable" in this sense is the Kemerovo region, which today has an industrial structure with a vivid "mono-dependence" from the coal mining industry, which already makes one think about the "rehabilitation" of the region through an integrated solution of the problem removing its primary acuteness.

One of the limiting factors in the Kemerovo region development is, in our opinion, a low diversification and "innovation" degree in strategic management of the regional economy, which, as it was noted, has a clear resource orientation (coal mining and low processing of natural resources). This was confirmed by the analysis of the Kemerovo region development strategy, where, in contrast to Sakhalin, primarily fundamental is the coal industry development.

We believe that diversification approach to "mono-region" management becomes particularly important in the recession of Russian economy. Current problems determine the 
need for the innovations development and implementation in management which should contribute to the complex development of the region.

It must be emphasized that diversification in management of narrow-specialized (coal mining) regions should be directed not just to the economy profile-changing, but rather to changing the economic structure. In this sense, we consider it necessary to transfer the center of gravity in the economic structure from the traditional for the region metallurgical, coal, petrochemical industries, without diminishing the importance of the latters, to new and emerging trends, such as services. Such an approach would solve the problem of promoting the region as an integrated product that includes both basic and supporting industries.

It is important to emphasize that the Kemerovo region has not only coal reserves, which put the ground for its industrial development (coal, chemical, metallurgical industry), but also significant natural and recreational resources, which, despite some structural changes in the regional economy are not fully used.

Differentiation of regions by various social and industrial-and-economic aspects, monostructure and low volatility of their development processes make it necessary to use individual forms, methods and strategic management approaches to identify, use and diversify the competitive advantages of every particular region [7] .

We believe that in order to solve the problem of region's promotion, to improve its investment climate and innovative management it is necessary to use regional marketing technology. It is advisable to direct the vector of economic development of the Kemerovo region in the direction of complex use of all available resources, taking into account their specificities and existing potential.

In this case, the marketing strategy of the Kemerovo region development should be based on the use of marketing tools, taking into account a possible "targeting" of the region and to become the basis for its promotion concept. The importance of marketing approach in the concept of complex promotion of the region, its sustainable development is dictated, in the first place, by increasing competition, both on the domestic and global markets.

In a number of works scholars have pointed to the need for using marketing and its tools in an innovative strategic development of the region together with the diversification policy in management [2, 8-12].

It is especially important to take into account that it is strengthening of the competitive advantages which in modern conditions becomes the main source of the regional strategy. In this sense, we should take into account the so-called cluster approach in management (marketing technology), which in our view is still not used in the strategic management of the region. The concept of cluster management of regional economy allows identifying the factors of competitive advantages of the region, contributes to the development of priority sectors defining the investment attractiveness of the region [13].

The cluster approach should be reasoned and, above all, by the fact that in this administration a regional innovation system is being formed. It is based on public - private partnerships, enhancing regional economy innovativeness and its investment attractiveness.

The cluster in our understanding will represent a region as a complex product, which management should be based on the regional concentration and combination of all available resources, integrated subjects of the regional economic network.

Proposed regional agglomeration will provide a synergistic effect, which determines its future competitiveness. At the same time, we believe that the clustering of the region will show the synergistic effect from a mutual combination of all the regional resources, industries and sectors of economy. The synergy can be calculated by appealing to nonlinear theory, in accordance with which a total combined effect is not equal to a single element impact $[14,15]$.

Using regression analysis method, we construct a model that takes into account not only the direct contribution in obtaining the impact effect, but also the combined effect of the 
elements of resource provision for management processes, in our case by the Kemerovo region.

The simulation results show that at the impact on regional social and economic system of $\mathrm{x}_{\mathrm{i}}, \mathrm{x}_{\mathrm{j}} \ldots$ parameters, the greatest positive synergistic effect can be observed when combining social policy, national economy, related to both the total income in the region and the profit from the organizations. The presented combination determines, in our view, management effect of clustering on the sustainable development of the region.

\section{Conclusion}

Based on the study the authors came to the following conclusion:

- The comparative analysis of strategies for the development of coal-mining regions of Russia showed that the basis for the sustainable development of the studied regions remains the coal industry, the strategy weakly represent other sectors of regional economy.

- The logic of scientific research in the field of strategic management of regional development allowed determining the need for management modernization;

- The problems identified in the strategic management of "mono-territories" (the Kemerovo region) indicate the inertia of its further development as a result of "monodependence" from the coal-mining industry;

- The cluster approach in coal-mining region management makes it possible to define it (region) as a complex product the management of which should be based on the ground of territorial concentration and combination of all available resources, integrated subjects of the regional economic network;

- The use of marketing technologies (clustering) in strategic management of coalmining region serves as a condition for the government regulation of economy as a whole;

- The calculation of synergetic effects of using clustering in management has proven the need for using marketing technologies (clustering) in the strategic management of coalmining region.

\section{References}

1. I. Ansoff, Strategic management (1989)

2. N.A. Zaruba, N.N. Egorova, Coal in the $21^{\text {st }}$ Century: Mining, Processing and Safety, 39 (2016)

3. V.M. Tumin, A.G. Koryakov, E.P. Nikiforova, World App Sci Journal 25, 6 (2013)

4. J.R Galbraith, Human Resource Management, 22, 63 (1983)

5. G. Johnson. Strategic Change and the Management Process (Black-well, 1987)

6. S.M. Puffer, D. McCarthy, O.S. Vikhansky, A. Naumov, Org. Dynamics. 34, 3 (2007)

7. A. Granberg, I. Zaitseva, Problems of Economic Transition, 45, 8 (2002)

8. V.M. Tumin, A.V. Polyarus, S.N. Lomachenko, A.S. Troshin, S.Y. Doroshenko, Biosciences Biotechnology Research Asia. 12(1), 445 (2015)

9. N.P. Rebrova, B.P. Volovikov, A.I. Kovalev, O.V. Frik, European Journal of Economics and Management Sciences, 2, 10 (2016)

10. P. Kothler, Business Horizons, 79 (2000)

11. D. Day, Strategic marketing (2002)

12. J. Hulbert, Norman, E. Toy, Journal of Marketing, 12 (2011)

13. J. Medina, M. Duffy, Journal of Product and Brand Management. 7(3), 223 (1998)

14. H. Sislakova, Acta Univ. Ags. Sil-vicult. Mendelianae Brunensis, 48(2), 129 (2000)

15. A. Thompson, Strategic management: Awareness and change (1990) 